\title{
Ensino híbrido na rede pública em tempos de pandemia: reflexões e possibilidades
}

\author{
Lucilaine Sotili $^{1}$ \\ Jessica Ferreira Stöer ${ }^{2}$ \\ Izoldi Klein Pinheiro ${ }^{3}$ \\ Dilva Bertoldi Benvenutti ${ }^{4}$
}

\begin{abstract}
Resumo:
O artigo apresenta os resultados da pesquisa acerca do ensino híbrido na rede pública municipal de um município do extremo oeste de Santa Catarina. O objetivo do estudo é refletir e agregar conhecimento à prática pedagógica de professores acerca do ensino híbrido. A pesquisa possui abordagem qualitativa. Quanto à sua natureza, se classifica como aplicada e, com base nos seus objetivos, o estudo pode ser considerado descritivo. Os resultados apontam que os professores que participaram da pesquisa demonstraram interesse em aprender e conhecer os aplicativos e recursos que foram propostos para implementar o ensino híbrido. No que se refere aos momentos de formação e aperfeiçoamento, manifestaram interesse e a necessidade de participar de oficinas e aperfeiçoamento, a fim de enriquecer sua prática pedagógica, uma vez que, os participantes não concordam totalmente que houve inovação com aulas remotas em virtude de considerarem que, tanto os professores como os alunos não estavam preparados para esse contexto.
\end{abstract}

\section{Palavras-chave:}

Inovação. Ensino híbrido. Formação. Tecnologias digitais.

\footnotetext{
1 Graduada em Licenciatura em Informática pela Universidade do Oeste de Santa Catarina - Unoesc São Miguel do Oeste. Professora de Educação Básica na Rede Estadual de Santa Catarina. E-mail: lucisotili@gmail.com ORCID iD: https://orcid. org/0000-0003-0801-7192

2 Graduada em Pedagogia pela Universidade do Oeste de Santa Catarina - Unoesc São Miguel do Oeste. Professora de Educação Básica na Rede Municipal de São Miguel do Oeste - SC. E-mail: jeh_stoer@hotmail.com ORCID iD: https://orcid. org/0000-0003-4454-5208

3 Mestre em Administração pela Universidade do Oeste de Santa Catarina. Professora na Universidade do Oeste de Santa Catarina. E-mail: izoldi.pinheiro@unoesc.edu.br ORCID iD: https://orcid.org/0000-0001-8317-1451

4 Doutora em Educação nas Ciências pela UNIJUÍ. Professora de TI do Programa de Mestrado em Educação da Universidade do Oeste de Santa Catarina, Campus de Joaçaba-SC. Linha de pesquisa Processos Educativos e do grupo de pesquisa Formação Docente e Práticas de Ensino. E-mail: dilva.benvenutti@unoesc.edu.br ORCID iD: https://orcid.org/0000-0002$1252-0287$
} 


\title{
Hybrid Teaching in public schools in times of pandemic: reflections and possibilities
}

\begin{abstract}
:
The article presents the results of research about Hybrid Education in the Municipal Public System of a city in the West of Santa Catarina State. This study aimed to ponder and further increase the knowledge on the pedagogical practice of teachers regarding the Hybrid Teaching system. The research had a qualitative approach. The nature of this research is classified as applied, and based on its goals, the study can be considered descriptive. The results show that the group of professors who participated in the research was interested in learning and knowing the applications and resources that were proposed to implement Hybrid Teaching. Regarding the moments of training and improvement, the participants expressed interest and the need to participate in workshops to improve and enrich their pedagogical methods. The participants did not fully agree that online classes were innovative because they considered that both teachers and students were not prepared for this context.
\end{abstract}

Keywords:

Innovation. Hybrid education. Training. Digital technologies.

\section{La enseñanza híbrida en las escuelas públicas en tiempos de pande- mia: reflexiones y posibilidades}

\section{Resumen:}

El artículo presenta los resultados de una investigación sobre la Educación Híbrida en el Sistema Público Municipal de una ciudad del occidente del estado de Santa Catarina. Este estudio tuvo como objetivo reflexionar y profundizar el conocimiento sobre la práctica pedagógica de los docentes sobre el sistema de enseñanza híbrida. La investigación tuvo un enfoque cualitativo. La naturaleza de esta investigación se clasifica como aplicada y, en función de sus objetivos, el estudio puede considerarse descriptivo. Los resultados muestran que los docentes que participaron en la investigación mostraron interés en aprender y conocer las aplicaciones y recursos que se propusieron para implementar la Enseñanza Híbrida. En cuanto a los momentos de formación y perfeccionamiento, los participantes expresaron interés y la necesidad de participar en talleres para mejorar y enriquecer sus métodos pedagógicos. Los participantes no coincidieron plenamente en que las clases online fueran innovadoras porque consideraron que tanto los profesores como los alumnos no estaban preparados para este contexto.

Palabras clave:

Innovación. Educación híbrida. Formación. Tecnologías digitales.

\section{Introdução}

No ano de 2020 iniciou-se uma nova abordagem pedagógica devido a pandemia da COVID19, provocando mudanças nos métodos de ensino e aprendizagem, principalmente nas questões que envolvem tecnologia na aprendizagem. A partir desse cenário, abordou-se com mais frequência o termo ensino híbrido, sendo que este método de ensino passou a ser percebido como uma solução para o momento de pandemia, o qual ensejou a necessidade de priorizar a saúde, sem deixar de lado a aprendizagem dos estudantes. O sistema educacional passou por processos de movimento intenso, as rotinas foram sacolejadas, o jeito de fazer foi revisado e os professores desafiados a fazer diferente. 
Denota-se que o ensino híbrido se fundamenta na ideia de mesclar o estudo em dois momentos: on-line e presencial. Para o momento on-line, pode-se fazer uso de tecnologias diversas como editores de vídeos, histórias em quadrinhos entre outros aplicativos que facilitam e auxiliam no momento da aprendizagem. No que tange às aulas presenciais (segundo momento), o professor é o mediador para que a aprendizagem se efetive.

Vygotsky (1998, p. 73) contribui dizendo:

[...] O uso de meios artificiais - a transição para a atividade mediada - muda, fundamentalmente, todas as operações psicológicas, assim como o uso de instrumentos amplia de forma ilimitada a gama de atividades em cujo interior as novas funções psicológicas podem operar. Nesse contexto, podemos usar o termo função psicológica superior, ou comportamento superior com referência à combinação entre o instrumento e o signo na atividade psicológica.

Demonstra-se aqui a responsabilidade e a necessidade de comprometimento dos educadores no contexto escolar, o desenvolvimento dos alunos através da aprendizagem mediada. O professor precisa reconhecer que os alunos possuem saberes que precisam ser valorizados e estimulados para sua evolução.

É importante destacar que, apesar de ser um método interessante em tempos de pandemia, essa nova modalidade de ensino trouxe para os educadores grandes desafios, desde aprender e conhecer as tecnologias, organizar o tempo, o planejamento, entre outros aspectos. Diante disto, os educadores buscaram novas formas de aprender e inovar para que seus alunos continuassem aprendendo, buscaram outras metodologias, procurando entender o que é inovação e de que forma poderiam adaptar suas práticas pedagógicas tanto no modo presencial como no modo on-line.

Para inovar é preciso deixar algumas práticas conservadoras de lado, ou seja, para que realmente se provoque mudanças na educação é necessário sair da zona de conforto. Conforme Leite, Genro e Braga (2011), a inovação pedagógica proporciona um pensamento novo e diferente, afastando o educador do comodismo e o direcionando a pensar além do que lhe era, até então, dito serem formas "normais" de agir e fazer. É ativar o cérebro e gerar inquietações.

Contudo, não basta querer apenas inovar sem estar aberto para o novo, é preciso que haja motivação e atitude. Nogaro e Battestin (2016) reconhecem que, quando se trata de mudanças e inovação, não se pode esquecer que as pessoas costumam ser resistentes ao novo. Elucida-se que as escolas mais inovadoras são aquelas que são mais abertas à comunidade escolar, ao grupo de professores que compartilham ideias, pois os conflitos são potencializadores para a mudança.

A partir disso, o artigo apresenta os resultados da pesquisa acerca do ensino híbrido na rede pública municipal de um município do extremo oeste de Santa Catarina, fazendo parte da aplicação e socialização dos conhecimentos construídos durante a Especialização em Inovação na Educação oferecida pela Universidade do Oeste de Santa Catarina - Unoesc -, por meio do Fumdes - Fundo de Apoio à Manutenção e ao Desenvolvimento da Educação Superior. O objetivo foi formar profissionais da educação na perspectiva da construção de conhecimentos teórico-metodológicos implicados na promoção da inovação no contexto educacional, considerando a incorporação de tecnologias, a pesquisa e as práticas escolares.

Nesta perspectiva, o objetivo da pesquisa foi refletir e agregar conhecimento à prática pedagógica de professores acerca do ensino híbrido. A escolha do tema vem ao encontro da necessidade atual dos professores, considerando o contexto da educação durante a pandemia, onde se faz necessário encontrar meios para que o conhecimento chegue aos alunos. Diante da impossibilidade de voltar para sala de aula com capacidade máxima, uma das alternativas encontradas é o ensino híbrido, que contempla o momento presencial entre professores e alunos na sala de aula e continua em casa onde o aluno dá continuidade ao estudo com a integração das tecnologias digitais. 
A pesquisa ocorreu no mês de novembro de 2020 e foi realizada por meio do contato remoto no Google Meet e WhatsApp em momentos síncronos e assíncronos com oito professores, sendo caracterizada pela abordagem qualitativa. Ademais, quanto à sua natureza, se classifica como aplicada e, com base nos seus objetivos, o estudo pode ser considerado descritivo.

Finalizadas as considerações introdutórias, na próxima seção destaca-se o uso das tecnologias digitais e aplicativos educacionais como ferramenta pedagógica no processo de aprendizagem dos docentes.

\section{Inovação na educação: aplicativos educacionais}

Integrar as mídias digitais foi algo protelado por muito tempo no contexto educacional, porém, a pandemia da COVID-19 fez com que se tornasse uma necessidade imediata. A disseminação descontrolada do vírus alterou significativamente o funcionamento regular das escolas e a maioria dos governos de todo o mundo fechou temporariamente as instituições educacionais na tentativa de conter o contágio. Diante disso, Conceição, Mezzaroba e Santos (2021, p. 1) afirmam que

a pandemia de COVID-19 impôs uma nova ordem, um outro ritmo para a humanidade, alterando a percepção de tempo, de estabilidade, motivando a construção de novos ritmos e formas de olhar e refletir sobre os mais diversos âmbitos de nossas vidas.

Conforme a Organização das Nações Unidas para Educação, Ciência e Cultura UNESCO (2021), um ano após o início da crise, a situação permanece desoladora: metade da população estudantil do mundo ainda é afetada pelo fechamento total ou parcial das escolas e quase um terço dos estudantes não têm acesso ao ensino à distância.

Segundo Silva Neta e Capuchinho (2017), com os avanços ocorridos nos últimos tempos, as tecnologias digitais da informação e comunicação apresentam-se como estimuladoras de grandes transformações sociais. Em consequência, esses avanços promovem alterações também para a educação, sendo que o ensino híbrido é uma possibilidade que vem despertando crescente interesse.

O ensino híbrido mescla o tempo, lugar, modo e o ritmo do estudo, e o meio digital é um aliado a esta metodologia que vem sendo usada neste novo cenário educacional provocado pela pandemia. Segundo Conceição, Mezzaroba e Santos (2021, p. 19):

Compreender esse contexto difícil gerado pela pandemia, focando o olhar quanto à experiência dos jovens nesse cenário - mas não se restringindo às análises apenas de psicólogos, infectologistas, virologistas e epidemiologistas, profissionais identificados com suas opiniões nas reportagens utilizadas - é papel dos professores e professoras que têm o compromisso com a formação dessa geração, mergulhando em seus microcosmos e aproveitando todo desvelamento do mundo social que a pandemia nos traz (principalmente quanto às desigualdades sociais no Brasil), que impactam fortemente jovens e sua possibilidade de futuro.

O uso das tecnologias no âmbito escolar foi uma das alternativas encontradas, mesmo que não abrangendo de forma igualitária todos os estudantes para dar continuidade aos estudos. Neste cenário, os docentes sentiram a necessidade de se reinventar e inovar nas suas práticas pedagógicas utilizando diversos recursos tecnológicos e aplicativos educacionais para trabalhar com seus alunos de forma remota. Segundo Pasini, Carvalho e Almeida (2020, p. 3):

A covid-19 nos levou a uma dessas situações emergenciais. A pandemia afastou os alunos presenciais, da educação básica e do ensino superior, das salas de aula. Os gestores educacionais ficaram naturalmente atônitos e a reação demorou um pouco a ocorrer. Surgiram, então, as 
necessidades de adaptação e de superação, tanto por parte da gestão, dos professores quanto pelos estudantes, incluindo toda a sociedade.

Conforme Pinheiro, Benvenutti e Favretto (2020), as mídias digitais se apresentam, no contexto da educação básica, como uma possibilidade de transformar os processos de ensino e aprendizagem, ampliando e aprofundando os conteúdos abordados. Integrar esses recursos na prática pedagógica representa falar a linguagem dos alunos, aproximar-se da realidade digital, conquistar atenção e engajamento no processo de aprendizagem e, assim, potencializar a construção do conhecimento.

Para Gadotti (2000), a escola é responsável pela formação de novas gerações que têm sido influenciadas pelas diferentes tecnologias. Para tanto, a escola e os professores são desafiados a organizar propostas de ensino que busquem auxiliar o aluno a construir o seu conhecimento por meio de usos tecnológicos. Surge espaço, então, para os softwares de autoria com suas interfaces interativas e de fácil utilização que fazem com que o usuário consiga abordar conteúdos e construir conhecimentos em diferentes formatos multimídias.

Em complemento, Moran (1999, p. 5) aduz que:

A educação escolar precisa compreender e incorporar mais as novas linguagens, desvendar os seus códigos, dominar as possibilidades de expressão e as possíveis manipulações. É importante educar para usos democráticos, mais progressistas e participativos das tecnologias que facilitem a evolução dos indivíduos.

O uso de softwares educacionais pelos docentes e alunos é uma das formas de colocar em prática a ideia defendida por Moran (1999). Existe uma diversidade de aplicativos que contemplam as mais variadas metodologias, entre elas, a criação de histórias em quadrinhos e edição de vídeos interativos.

Quanto aos quadrinhos, a trajetória histórica é bem antiga, como afirmam Iannone e Iannone (1994, p. 10), ao citarem que "estudiosos apontam as inscrições que nossos antepassados deixaram nas cavernas, no período pré-histórico, como a origem mais remota das histórias em quadrinhos". No entanto, as HQ atualmente conhecidas começaram a surgir no final do Século XIX, na Europa e nos Estados Unidos, expandindo-se, posteriormente, para outros países (MORAN, 1999).

Os quadrinhos, segundo Moya (1977, p. 110), "são um conjunto e uma sequência". São compostos por quadros que combinam dois meios de comunicação diferentes: o desenho e o texto. A linguagem e os elementos dos quadrinhos podem ser aliados do ensino. A união do texto com a imagem facilita a compreensão dos conceitos que ficariam abstratos se relacionados unicamente com as palavras (SANTOS, 2001).

A utilização dos quadrinhos também pode ser de grande importância para iniciar a prática da leitura com crianças, podendo despertar o prazer em ler.

Conforme Alves (2001, p. 7):

A leitura de histórias em quadrinhos pode contribuir para a formação do gosto pela leitura porque ao ler histórias em quadrinhos a criança envolve-se numa atividade solitária e não movimentada por determinado período de tempo, que são características pouco frequentes nas atividades de crianças pré-escolares ou no início da escolarização. Também porque, estando mais próximas da forma de raciocinar destas crianças, elas podem mais facilmente lê-las, no sentido de retirar delas significados, o que seria menos provável com outros tipos de leitura. Além disso, pode-se esperar que uma criança para quem a leitura tenha se tornado uma atividade espontânea e divertida, esteja mais motivada a explorar outros tipos de textos (com poucas ilustrações), do que uma criança para quem esta atividade tenha sido imposta e se tornado enfadonha. 
Devido a todas as vantagens citadas pelos autores supracitados quanto ao uso das histórias em quadrinhos e a grande expansão do uso das tecnologias na educação, muitas ferramentas foram criadas, entre elas o Pixton, uma ferramenta on-line que permite a criação de histórias em quadrinhos. Referida ferramenta possui uma variedade de cenários, objetos e personagens disponíveis para que os alunos possam desenvolver sua criatividade, bem como aos professores para implementar sua metodologia de ensino e criar atividades mais atrativas.

Apresentados os principais aspectos teóricos envolvendo o tema, a próxima seção traz os resultados obtidos com a aplicação da pesquisa com professores da rede pública de ensino de um município do extremo oeste de Santa Catarina.

\section{Resultados}

O primeiro momento da pesquisa contemplou o levantamento de dados com os participantes acerca de inquietações a respeito do tema, evidenciando-se a necessidade de momentos de capacitação com encaminhamento de recursos práticos, visando à concretização do ensino híbrido de forma eficaz. Diante disso, promoveu-se o planejamento de 8 horas de capacitação a fim de contemplar a necessidade evidenciada.

A capacitação, que faz parte da pesquisa, foi realizada de forma remota por meio do Google Meet e WhatsApp, em momentos síncronos e assíncronos, com objetivo de apresentar aplicativos e formas de integração destes meios à prática pedagógica.

O primeiro recurso trabalhado foi a história em quadrinhos, sendo que, com o objetivo de despertar o interesse dos participantes, foi enviado um convite no grupo de WhatsApp, em forma de tirinha desenvolvido no aplicativo Pixton (Imagem 1), o qual foi trabalhado, posteriormente, durante a capacitação.

Imagem 1 - Convite desenvolvido na ferramenta Pixton

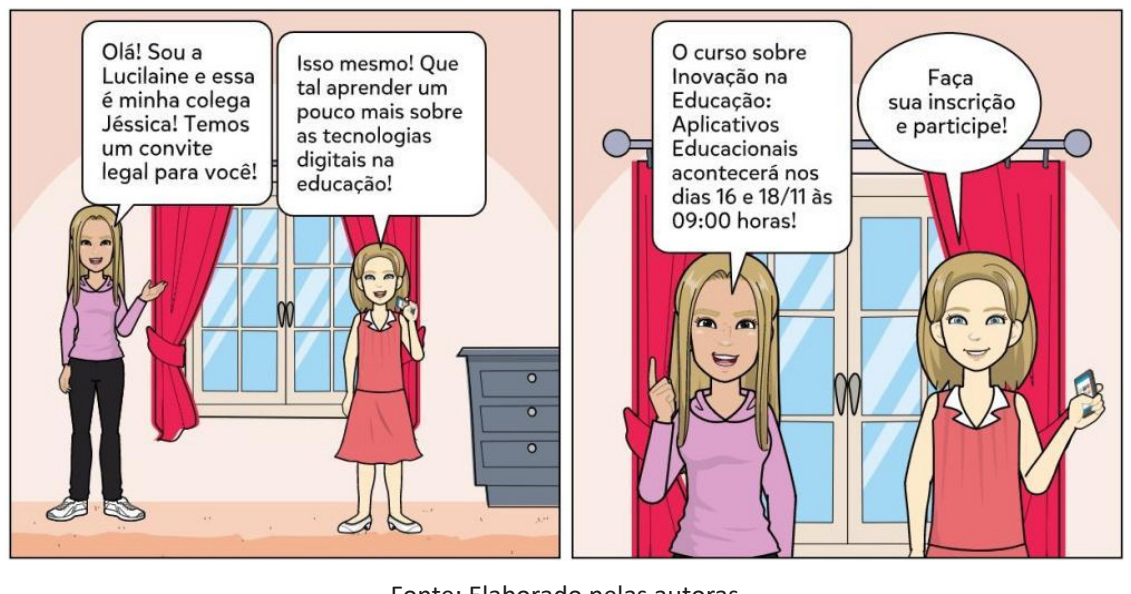

Fonte: Elaborado pelas autoras.

Durante a capacitação, os participantes foram desafiados a criar uma história em quadrinhos, permitindo que tivessem a oportunidade de instalar e trabalhar com o aplicativo. Além disso, foram compartilhadas diversas formas de trabalhar com esse recurso.

Durante o levantamento de dados, também se identificou que o vídeo foi um recurso importante durante a aula remota, além de ser um recurso utilizado pelos alunos quando pesquisam algum assunto. Pensando nisso e, com o objetivo de promover a interatividade, utilizou-se o software Edpuzzle, que é uma plataforma on-line e gratuita, que permite importar vídeos e adicionar enquetes e outros recursos com o intuito de criar interatividade com quem está assistindo. 
Assim, foram enviados aos participantes vídeos acerca do tema que estava sendo trabalhado, sendo que esses vídeos foram editados com o aplicativo. Dessa forma, foi despertando o interesse dos participantes e, ao mesmo tempo, introduzindo o assunto, caracterizando, assim, o momento on-line da aula híbrida. No momento síncrono da capacitação, trabalhou-se o aplicativo para edição dos vídeos. Além disso, abordou-se a contextualização e discussão acerca do ensino híbrido, uma vez que esses aplicativos são opções que oferecem elementos para colocar em prática esse modelo de ensino.

Durante a capacitação, além de acompanhar o desenvolvimento e tirar dúvidas, foi disponibilizado um tutorial com passo a passo de como usar os aplicativos, permitindo que todos os participantes conseguissem editar seus vídeos e criar histórias em quadrinhos. O resultado foi compartilhado com os colegas. Os participantes avaliaram de forma positiva os aplicativos utilizados, principalmente, por se tratar de uma novidade, além da facilidade de uso, bem como pela contribuição metodológica que proporcionam, afirmando que usarão futuramente em suas práticas pedagógicas.

Dessa forma, é possível observar que, de fato, a capacitação com encaminhamento de recursos que podem ser usados no dia-a-dia, principalmente os que envolvem o uso da tecnologia digital, agrega positivamente no desenvolvimento de metodologias inovadoras pelos docentes e, consequentemente, contribui de forma geral para o processo de ensino e aprendizagem.

Dando continuidade, para levantar mais dados que pudessem permitir a reflexão e complementar o estudo, foi disponibilizado um questionário para os participantes responderem acerca de sua perspectiva em relação ao tema abordado.

Foi questionado se os participantes sentiam necessidade de mais momentos de formação que contemplassem o desenvolvimento de atividades de aprendizagem na prática, tendo como opções de resposta: "Sim", "Não" e "Em partes". Todos responderam a alternativa "sim". Esse resultado vem ao encontro da ideia das autoras Schlemmer, Kersch e Oliveira (2020), que afirmam a importância do desenvolvimento de competências técnico didático-pedagógicas, em outras palavras, o saber fazer docente, acrescentando-se que, na atualidade, há a necessidade de propor processos formativos pensados numa perspectiva de coengendramento, ou seja, não se trata de formar o professor de maneira fragmentada, isolada, mas de enxergá-lo junto com tudo que faz, situado dentro de um sistema.

Abordou-se na questão seguinte a perspectiva dos participantes sobre o ensino híbrido no retorno das aulas, tendo como opções de resposta: "será uma boa alternativa, uma vez que inova o processo e potencializa o processo de ensino e aprendizagem" ou "não vejo benefícios em sua aplicabilidade". Como resultado, $80 \%$ dos participantes responderam positivamente, ou seja, acreditam que será uma boa alternativa, promovendo a inovação e potencializando a aprendizagem.

Diante disso, Silva Neta e Capuchinho (2017) afirmam que, com os avanços ocorridos nos últimos tempos, as tecnologias digitais da informação e comunicação apresentam-se como estimuladoras de grandes transformações sociais. Em consequência, esses avanços provocam alterações também para a educação, e o ensino híbrido é uma possibilidade que vem despertando crescente interesse e sua inserção altera toda uma cultura de metodologias, gestão, práticas docentes, crenças de alunos e professores. Deixa-se de lado a memorização mecânica e atribui-se significado à análise, busca, seleção, compartilhamento, bem como a necessidade de acesso às tecnologias para promover a interatividade, o compartilhamento de experiências e a articulação entre as atividades propostas.

As questões seguintes abordaram a temática do uso da tecnologia no período de pandemia e a necessidade de inovação na educação, apresentando os seguintes questionamentos:

» “A COVID-19 provocou inovação no processo de ensino”;

" "Entendo que não houve inovação no processo de ensino com as aulas remotas, uma vez que professores, escola e alunos não estavam preparados e capacitados para integração das tecnologias digitais"; 
» "A tecnologia digital proporcionou benefícios no desenvolvimento das aulas remotas durante o período pandêmico" ou

" "As aulas remotas possuem a mesma qualidade que as aulas presenciais".

Os resultados encontram-se representados no Gráfico 1.

Gráfico 1 - questionamentos sobre uso das tecnologias

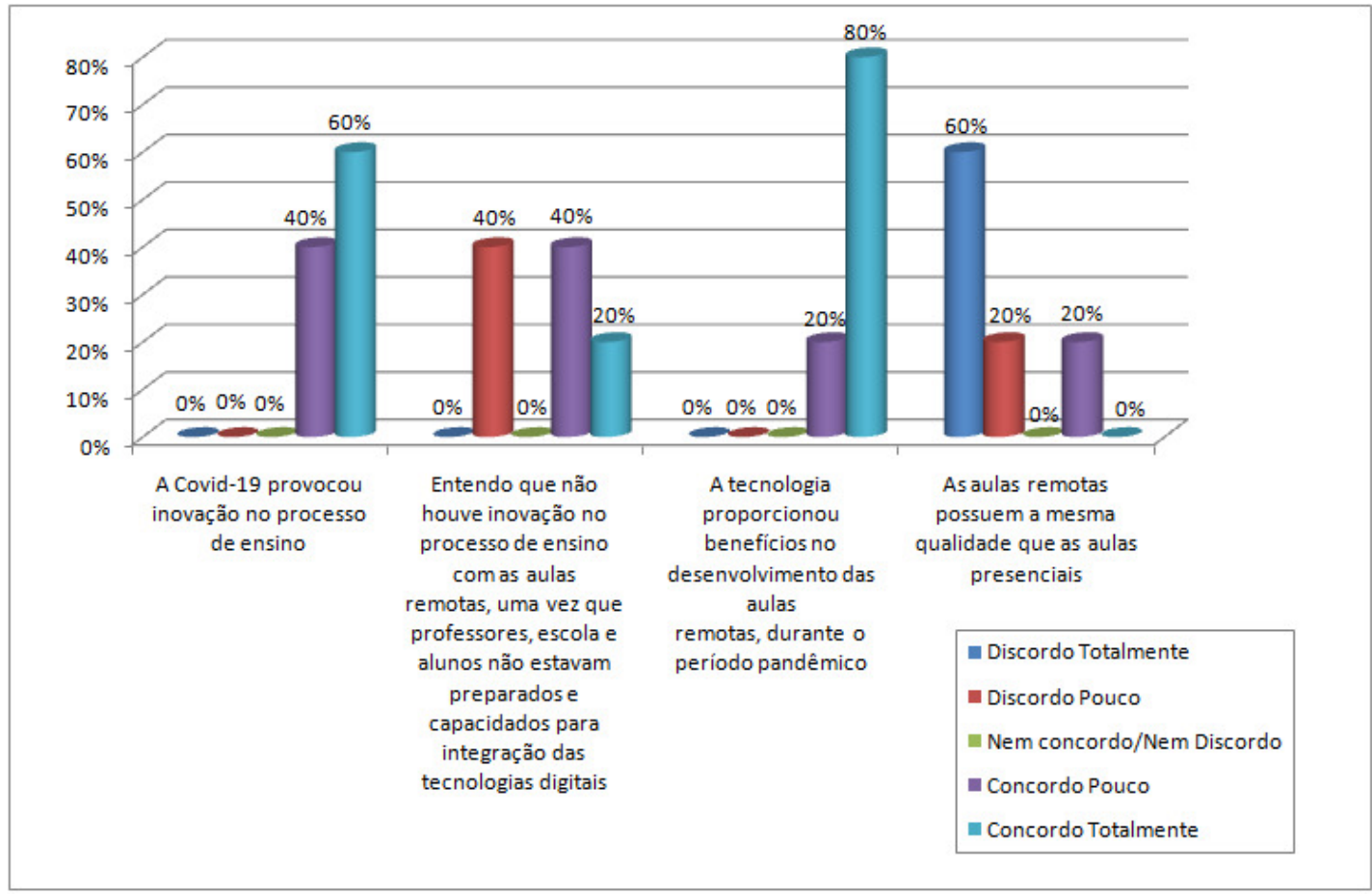

Fonte: Elaborado pelas autoras.

Os dados demonstram que os participantes acreditam que a pandemia provocou inovação no processo de ensino, mas nem todos concordam que houve inovação com aulas remotas, visto os professores e alunos não estarem preparados. Este fato demonstra que usar as tecnologias digitais não garante que se tenha inovação. Conforme Modelski, Giraffa e Casartelli (2019, p. 13):

Na cibercultura, as possibilidades de conexões entre as pessoas e entre as informações ocorrem mediadas/apoiadas por artefatos tecnológicos conectados à internet. Esta é a grande diferença: não são os artefatos digitais que permitem o estabelecimento da cultura digital que nos rodeia; a conexão em si é que oferta os desafios e possibilidades que nos desestabilizam e nos permitem reavaliar e pensar novas práticas.

Assim, conforme os autores, não são as ferramentas tecnológicas que estabelecem a cultura digital e sim a conexão em si. Levando para o contexto da inovação na educação, a tecnologia é apenas uma ferramenta para que metodologias inovadoras sejam desenvolvidas. Mesmo assim concordam que a tecnologia proporcionou benefícios no desenvolvimento das aulas remotas mesmo não concordando que as aulas remotas possuem a mesma qualidade que as aulas presenciais.

Por fim, questionou-se acerca da situação atual, apresentando a seguinte questão: Qual a maior lição da pandemia da COVID para a educação? As respostas estão indicadas no Quadro 1. 
Quadro 1 - Lição da COVID-19 para educação

\begin{tabular}{|l|c|}
\hline Participante 1 & Reinventar-se. \\
\hline Participante 2 & Nos reinventando, inovando e buscando uso das tecnologias. \\
\hline Participante 3 & Quanto devemos desenvolver mais as áreas tecnológicas. \\
\hline Participante 4 & Uma das lições foi adequar-se em tão pouco tempo para o ensino remoto. \\
\hline Participante 5 & Família e escola devem trabalhar unidas sempre. \\
\hline
\end{tabular}

Pode-se perceber no relato dos participantes, conforme Quadro 1, que a tecnologia foi citada sendo uma das formas de se reinventar na educação diante da situação da pandemia, bem como a preocupação em buscar conhecimento sobre as áreas tecnológicas.

Finalizadas as apresentações dos resultados da pesquisa, passa-se às considerações finais.

\title{
Considerações finais
}

\author{
Sim, sou eu, eu mesmo, tal qual resultei de tudo... \\ Quanto fui, quanto não fui, tudo isso sou. \\ Quanto quis, quanto não quis, tudo isso me forma.
}

Fernando Pessoa

A inovação na educação vai muito além de apenas utilizar as tecnologias digitais. É necessário que o educador mude suas práticas e metodologias utilizando os recursos tecnológicos como uma ferramenta para essa inovação se efetivar.

Sabe-se que inovar não é uma tarefa fácil e simples, pois precisam de recursos, materiais, estudos e possibilidades para que haja essa mudança na educação básica, havendo o necessário amparo e apoio aos educadores, bem como às famílias e estudantes também, visto que todos precisam estar envolvidos no processo.

No que se refere ao uso dos aplicativos educacionais constatou-se que os educadores estão abertos para o aprendizado de novas tecnologias e estão engajados a utilizar novos recursos. Além disso, os educadores mantêm interesse em aprender e utilizar com os estudantes essas novas ferramentas de ensino.

Percebeu-se que houve uma aceitação e interesse por parte dos educadores em aprender a utilizar os aplicativos que foram abordados, atendendo ao objetivo deste estudo que visou refletir e agregar conhecimento à prática pedagógica de professores acerca do ensino híbrido.

Vivemos uma experiência marcante, um tempo diferente, muitos colegas professores aderindo, outros quem sabe fugindo. Nem tudo o que somos é resultado do que desejamos, somos e escolhemos. Pertencemos à soma de muitas coisas estranhas, belas e encantadoras. Legítimos seres humanos em evolução, construindo imagens diferentes em tempos pandêmicos, quem sabe inovadoras, criativas, capazes de revolucionar a educação. 


\section{Referências}

ALVES, José Moysés. Histórias em quadrinhos e educação infantil. Psicologia: Ciência e Profissão, Brasília, DF, v. 21, n. 3, set. 2001. Disponível em: https://doi.org/10.1590/S1414-98932001000300002. Acesso em: 24 abr. 2021.

CONCEIÇÃO, Daniel Machado da; MEZZAROBA, Cristiano; SANTOS, Marcos Rogério dos. As juventudes na mídia durante a pandemia COVID-19: compreender para educar. Cadernos do Aplicação, Porto Alegre, v. 34, n. 1, jan./jun. 2021. Disponível em: https://seer.ufrgs.br/CadernosdoAplicacao/article/view/111195. Acesso em: 03 maio 2021.

GADOTTI, Moacir. Perspectivas atuais da educação. Porto Alegre: Artes Médicas, 2000.

IANNONE, Leila Rentroia; IANNONE, Roberto Antonio. O mundo das histórias em quadrinhos. São Paulo: Moderna, 1994.

LEITE, Denise Balarine Cavalheiro; GENRO, Maria Elly Herz; BRAGA, Ana Maria e Souza. Inovações pedagógicas e demandas ao docente na universidade. In: LEITE, Denise Balarine Cavalheiro; GENRO, Maria Elly Herz; BRAGA, Ana Maria e Souza (org.). Inovação e pedagogia universitária. Porto Alegre: UFRGS, 2011. p. 19-39.

MODELSKI, Daiane; GIRAFFA, Lúcia M. M.; CASARTELLI, Alam de Oliveira. Tecnologias digitais, formação docente e prática pedagógica. Educação \& Pesquisa, São Paulo, v. 45, mar. 2019. Disponível em: http://dx.doi.org/10.1590/ s1678-4634201945180201. Acesso em: 04 maio 2021.

MORAN, José Manuel. O uso das novas tecnologias da Informação e da Comunicação na EAD: uma leitura crítica dos meios. São Paulo: Ministério da Educação, 1999. Disponível em: http://portal.mec.gov.br/seed/arquivos/pdf/T6\%20 TextoMoran.pdf. Acesso em: 24 abr. 2021.

MOYA, Álvaro de. História da história em quadrinhos. 3. ed. São Paulo: Perspectiva, 1977.

NOGARO, Arnaldo; BATTESTIN, Cláudia. Sentidos e Contornos na Inovação na Educação. Holos, Natal, ano 32, v. 2, 2016.

PASINI, Carlos Giovani Delevati; CARVALHO, Élvio de; ALMEIDA, Lucy Hellen Coutinho. A educação híbrida em tempos de pandemia: algumas considerações. Santa Maria: Observatório Socioeconômico da COVID-19: UFSM, 2020.

PESSOA, Fernando. Álvaro de Campos (heterônimo). Sim, sou eu, eu mesmo, tal qual resultei de tudo. Lisboa: Ática, 1944 (imp. 1993) Disponível em: http://arquivopessoa.net/textos/2567. Acesso em: 15 fev. 2021.

PINHEIRO, Izoldi Klein; BENVENUTTI, Dilva Bertoldi; FAVRETTO, Jacir. Ambiente de aprendizagem: conhecimento tecnológico pedagógico do conteúdo. Revista Eletrônica de Educação, São Carlos, v. 14, p. 1-16, jan./dez. 2020. Disponível em: http://www.reveduc.ufscar.br/index.php/reveduc/article/view/3765. Acesso em: 23 abr. 2021.

SANTOS, Roberto Elísio dos. Aplicações da História em Quadrinhos. Comunicação \& Educação, São Paulo, n. 22, p. 46-51, set./dez. 2001. Disponível em: https://www.revistas.usp.br/comueduc/article/view/36995. Acesso em: 24 abr. 2021.

SCHLEMMER, Eliane; KERSCH, Dorotea; OLIVEIRA, Lisiane. Formação de professores-pesquisadores em contexto híbrido e multimodal: Desafios da docência no stricto sensu. Revista Tecnologias na Educação, Belo Horizonte, ano 12, v. 33, dez. 2020. Disponível em: https:/tecedu.pro.br/wp-content/uploads/2020/12/Art10-Ano-12-vol33-Dezembro-2020.pdf. Acesso em: 23 abr. 2021

SILVA NETA, Mariana da; CAPUCHINHO, Adriana Carvalho. Educação Híbrida: Conceitos, Reflexões e Possibilidades do Ensino Personalizado. In: CONGRESSO SOBRE TECNOLOGIAS NA EDUCAÇÃO, 2., 2017, Mamanguape. Anais [...]. Mamanguape: CTRL E, 2017.p. 148-156. Disponível em: http://ceur-ws.org/Vol-1877/CtrlE2017_AC_13_62. pdf. Acesso em: 23 abr. 2021.

UNESCO. Conectividade, gênero e professores: como a Coalizão Global de Educação está apoiando a recuperação da aprendizagem na COVID-19. Paris: Unesco, 2021. Disponível em: https://pt.unesco.org/news/conectividade-genero-e-professores-como-coalizao-global-educacao-esta-apoiando-recuperacao-da. Acesso em: 14 abr. 2021.

VYGOTSKY, Lev Semionovitch A Formação Social da Mente. 6. ed. Tradução de José Cipolla Neto, Luis S. M. Barreto e Solange C. Afeche. São Paulo: Martins Fontes, 1998.

Data de submissão: 19/05/2021

Data de aceite: 04/06/2021 